\title{
Applied Magnetism: A Supply-Driven Materials Challenge
}

\author{
ORLANDO RIOS ${ }^{1,3}$ and SCOTT K. McCALL ${ }^{2,4}$ \\ 1.-Oak Ridge National Laboratory, Oak Ridge, TN 37831, USA. 2.-Lawrence Liver- \\ more National Laboratory, Livermore, CA 94551, USA. 3.—e-mail: rioso@ornl.gov. 4.—e-mail: \\ mccall10@llnl.gov
}

Permanent magnets are important in many green energy technologies including wind turbine generators and hybrid-electric vehicle motors. For these applications, volume and weight are important factors driving the overall design, and therefore a high energy density, or energy product, is an important figure of merit. This quantity defines the magnetic energy contained in a given volume of material, and so higher energy density magnets enable smaller, lighter applications. Currently, the most powerful magnets suitable for commercial purposes contain rare earth elements (REE), usually neodymium and dysprosium in the neodymiumiron-boride class of magnets. However, for select applications, often requiring high temperatures, samarium cobalt is the alloy of choice. These magnets have energy densities several times greater than their nearest non-REE-based competitor, which for some applications is the defining factor in creating a viable device. The global supply of these REE is overwhelmingly produced in China, which in 2015 mined more than ten times as much as the next largest producer (Australia). Such market domination effectively creates a single source of supply, leaving industries which rely on REE consumption susceptible to price shocks and supply disruptions of these critical materials. This supply sensitivity may act as a drag on the adaptation rate of green energy technologies, particularly for large-scale users.

This issue of $J O M$ includes several articles addressing these critical materials challenges from a variety of perspectives.

An article by Sims et al. on "Cerium-Based Intermetallic Strengthened Aluminum Casting Alloy: High Volume Co-Product Development" presents the case for a new high cerium content castable alloy that holds promise to outperform

Orlando Rios is the JOM advisor for the Magnetic Materials Committee of the TMS Functional Materials Division, and guest editor for the topic Applied Magnetism: A Supply-Driven Materials Challenge: Part II in this issue. many current $\mathrm{Al}$ alloys, particularly at higher temperatures, where it may find application in light-weight vehicles in the transportation sector, thereby improving fuel economy. If this alloy is widely adopted, the potential new demand for cerium may change it from a by-product to a coproduct that is cost and performance competitive with traditional alloying elements. Partial market penetration is expected to impact the economics of rare earth mining across the globe. The economic impact is further explored in an article by Nguyen and Imholte entitled "China's Rare Earth Supply Chain: Illegal Production, and Response to new Cerium Demand" where they project that successful implementation of this alloy will exceed the capability for China to meet demand for $\mathrm{Ce}$ within a decade.

Iyer and Vedantam look more broadly at materials criticality in, "A Market Impact Model for Critical Material Intensity Reduction Technology." They explore the market benefit of technologies that reduce critical materials intensity in a model system focused on permanent magnets, both when the system is supply constrained and in the optimal production regime. Their model provides insight into the value of new intellectual property that addresses material criticality. A different economic perspective is explored by Smith and Eggert in "Multifaceted Material Substitution: The Case of NdFeB Magnets, 2010-2015." They consider a number of substitutional pathways that producers and consumers of $\mathrm{NdFeB}$ magnets might have employed in response to the price increases of 2010-2011. Their research suggests that the price shock may have driven several innovations that could partially attenuate future shock sensitivity.

In an effort to identify promising new magnet materials, Geng and co-workers report on "Bulk Combinatorial Synthesis and High Throughput Characterization for Rapid Assessment of Magnetic Materials: Application of Laser Engineered Net Shaping (LENS ${ }^{\mathrm{TM}}$ )" They employ Fe and Co to demonstrate a method for efficiently exploring 
phase diagrams in both structure and thermodynamic properties using automated synthesis and characterization capabilities. This methodology shows promise for investigating ternary, quaternary, and more complicated material systems, resulting in libraries of their structure-property relationships. This method may yield new tools for identifying promising regions of phase space for property optimization.

Advanced manufacturing techniques are explored by Paranthaman et al. in "Binder Jetting: A Novel NdFeB Bonded Magnet Fabrication Process." They show promising results for the design of near-netshaped bonded magnets without need for dies or other customized tooling. With bimodal or multimodal particle sizes, higher magnet densities may be possible. This may also offer a path for recycling old magnets from e-waste without the need for extensive material reprocessing.

This work was supported by the Critical Materials Institute, an Energy Innovation Hub funded by the U.S. Department of Energy, Office of Energy Efficiency and Renewable Energy, Advanced Manufacturing Office. Work prepared by LLNL under Contract DE-AC52-07NA27344 and by ORNL under contract DE-AC05-00OR22725.

The following papers being published under the topic of Applied Magnetism: A Supply-Driven Materials Challenge: Part II provide excellent details and research on the subject. To download any of the papers, follow the url http://link.springer.com/jour nal/11837/68/7/page/ 1 to the table of contents page for the July 2016 issue (vol. 68, no. 7).

- "Cerium-Based, Intermetallic-Strengthened Aluminum Casting Alloy: High-Volume Co-product Development" by Zachary C. Sims, D. Weiss, S.K. McCall, M.A. McGuire, R.T. Ott, Tom Geer, and Orlando Rios

- "China's Rare Earth Supply Chain: Illegal Production, and Response to New Cerium Demand" by Ruby Thuy Nguyen and D. Devin Imholte

- "A Market Model for Evaluating Technologies That Impact Critical Material Intensity" by Ananth V. Iyer and Aditya Vedantam

- "Multifaceted Material Substitution: The Case of NdFeB Magnets, 2010-2015" by Braeton J. Smith and Roderick G. Eggert

- "Bulk Combinatorial Synthesis and High Throughput Characterization for Rapid Assessment of Magnetic Materials: Application of Laser Engineered Net Shaping (LENS ${ }^{\mathrm{TM}}$ )" by J. Geng, I.C. Nlebedim, M.F. Besser, E. Simsek, and and R.T. Ott

- "Binder Jetting: A Novel NdFeB Bonded Magnet Fabrication Process" by M. Parans Paranthaman, Christopher S. Shafer, Amy M. Elliott, Derek H. Siddel, Michael A. McGuire, Robert M. Springfield, Josh Martin, Robert Fredette, and John Ormerod 